\section{Posterior approach to the lumbar plexus combined with a sciatic nerve block using lidocaine}

\author{
Juliana Farny MD, ${ }^{*}$ Michel Girard MD MHPE FRCPC, $\uparrow$ \\ Pierre Drolet MD FRCPC $\dagger$
}

A combination of lumbar plexus block, by a posterior technique, and sciatic nerve block can be a useful technique for outpatient anaesthesia. The purpose of this study was to examine the clinical characteristics of these blocks using lidocaine and to measure the serum lidocaine concentrations. Forty-five patients, undergoing lower extremity surgery, were studied. Sciatic nerve and lumbar plexus blocks were made with lidocaine, $680 \mathrm{mg}$ with adrenaline $0.3 \mathrm{mg}$. For each patient the following data were collected: weight, age, sex, site of surgery, time to perform each block, needle depth, speed of onset of the sensory and motor blocks in the territories of the sciatic, femoral, obturator and lateral cutaneous (sensory) nerves and postoperative analgesic requirements. Lidocaine serum concentrations were measured in ten of these patients at $0,2,5,10,30,60$, 90 and 120 min after the second block. Analgesia was complete in $88 \%(40 / 45)$ of the patients. The remaining five patients needed analgesics (fentanyl $150 \mu \mathrm{g}$ or less). Despite the high dose of lidocaine, the serum concentrations were within safe limits (mean $\pm S D)\left(C_{M A X}=3.66 \pm 2.21 \mu \mathrm{g} \cdot \mathrm{ml}^{-1}\right)$. Only one patient had a serum concentration $>5 \mu \mathrm{g} \cdot \mathrm{ml}^{-1}\left(C_{M A X}\right.$ $=9.54 \mu \mathrm{g} \cdot \mathrm{ml}^{-1}$ ). This was associated with a contra-lateral extension of the block. We conclude that this combination of blocks is a valuable alternative for unilateral lower extremity anaesthesia. However, clinicians must be aware of the implications of a contra-lateral extension of the block.

Key words

ANAESTHETIC TECHNIQUES: regional, lumbar plexus

block, sciatic nerve block;

ANAESTHETICS: local, lidocaine.

From the Département d'anesthésie-réanimation, †Hôpital Maisonneuve-Rosemont et Université de Montréal, Montréal, Québec and *CHRU de Strasbourg, France.

Address correspondence to: Dr Michel Girard, Département d'anesthésie-réanimation, Hôpital Maisonneuve-Rosemont, 5415 boul. L'Assomption, Montréal, Québec, H1T 2M4.

Astra Pharma Inc provided financial support.

Accepted for publication 3rd March, 1994.
Le bloc du plexus lombaire, par voie postérieure, combiné au bloc du nerf sciatique, peut être utile en chirurgie d'un jour. Le but de ce travail est d'étudier les caractéristiques cliniques de cette combinaison de blocs en utilisant la lidocaïne et de mesurer les taux sériques de lidocaïne. Quarante-cinq patients qui ont subi une chirurgie du membre inférieur en utilisant cette technique anesthésique ont été étudiés. Des blocs du nerf sciatique et du plexus lombaire ont été faits à l'aide de 680 mg de lidocaïne adrénalisée $(0.3 \mathrm{mg})$. Pour chaque patient les données suivantes ont été recueuillies: poids, âge, sexe, site de lintervention, temps pour faire les blocs, profondeur des nerfs, temps d'installation des blocs moteurs et sensitifs dans les territoires des nerfs sciatique, fémoral, obturateur et fémoro-cutané (sensitif) et les besoins postopératoires en analgésiques. Les taux sériques de lidocaïne ont été mesurés chez dix de ces patients à $0,2,5,10,30,60,90$ et $120 \mathrm{~min}$ après le deuxième bloc. Dans $88 \%$ des cas (40/45) le bloc était complet. Les autres patients ont nécessité l'emploi d'analgésiques (fentanyl $\leq 150$ $\mu \mathrm{g}$ ). Malgré la dose élevée de lidocaïne employée, les taux sériques mesurés étaient dans les limites acceptables $\left(C_{M A X}=3,66\right.$ $\left.\pm 2,21 \mu \mathrm{g} \cdot \mathrm{ml}^{-1}\right)$. Un seul patient a présenté des valeurs dépassant $5 \mu \mathrm{g} \cdot \mathrm{ml}^{-1}\left(C_{M A X}=9,54 \mu \mathrm{g} \cdot \mathrm{ml}^{-1}\right)$ associées à un débordement controlatéral du bloc. Nous concluons que l'association des blocs du plexus lombaire et du nerf sciatique constitue une alternative acceptable pour l'anesthésie du membre inférieur. Une attention particulière doit cependant être accordée aux patients où la distribution du bloc est bilatérale.

Winnie is responsible for the original description of the two principal techniques of lumbar plexus block. The 3-in-1 block ${ }^{1}$ dates back to 1973 while the posterior approach, based on eliciting paraesthesia, was described one year later. ${ }^{2}$ The clinical potential of this second technique did not receive early recognition. Technically more difficult than the 3-in-1, it also has a similar shortcoming to the 3-in-1 in that it can rarely be used alone for surgery of the leg. Chayen, ${ }^{3}$ in 1976 , described a second posterior technique, based on loss of resistance. In 1989, Parkinson $^{4}$ demonstrated that a posterior technique was superior 
to the 3-in-1 for the number of nerves blocked. Dalens ${ }^{5}$ published the first study that compared the two posterior techniques. However, he modified Winnie's and Chayen's techniques, replacing seeking paraesthesia and loss of resistance with neurostimulation. He demonstrated that Winnie's technique was superior with regard to ease of execution and overall success rate.

The purpose of this study was to give a better description of the posterior lumbar plexus block and to define its clinical potential when combined with a sciatic nerve block. The combination of these two blocks is necessary to provide anaesthesia to the entire lower extremity. This is the first study of this combination of blocks using lidocaine. The work has two parts: the prospective study of the combined use of lumbar plexus and sciatic nerve block for lower extremity surgery and a serum concentration study to demonstrate if the lidocaine concentration is within values generally agreed as safe,

\section{Methods}

The protocols were reviewed and approved by the research and ethics committee of our institution. Informed consent, written for the serum lidocaine analysis, was obtained from all patients.

\section{Combined blocks technique}

Forty-five (45) patients, undergoing operations on a lower extremity were studied. For all patients, the anaesthesia technique was a combination of lumbar plexus and sciatic nerve blocks. After placing an intravenous catheter and basic monitoring (ECG, NIBP, $\mathrm{SpO}_{2}$ ) the patient was turned to the lateral position (Sim's position), with the operated side uppermost (Figure 1). To facilitate block execution, fentanyl citrate and midazolam were administered. Lumbar plexus block was performed according to Winnie's ${ }^{2}$ technique as modified by Dalens. ${ }^{5} \mathrm{~A}$ Tefloncoated stimulating needle (Stimuplex $100-150 \mathrm{~mm}$ ) was introduced perpendicularly to all cutaneous planes at the intersection of a transverse line, between the upper border of the iliac crests, and a longitudinal line parallel to the spine passing through the posterior superior iliac spine (Figure 1).

The sciatic nerve block was based on Labat's ${ }^{6}$ technique. In the Sim's position, the same needle was inserted at right angle to all cutaneous planes at the caudal end of a 3 to $5 \mathrm{~cm}$ line originating from, and perpendicular to, the middle of a line that unites the greater trochanter and the posterior superior iliac spine (Figure 2). In each case, neural structures were identified with the help of a neurostimulator using a stimulus of 0.5 to $1.0 \mathrm{~mA}$ at $1 \mathrm{~Hz}$. Movements of the quadriceps femoris were sought to identify the lumbar plexus while contractions of the gastrocnemius (foot plantar flexion) and/or tibialis an-

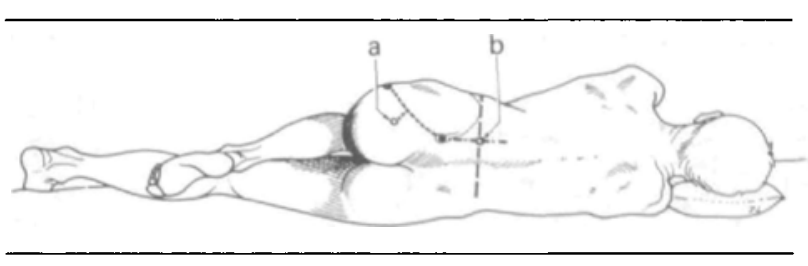

FIGURE 1 Patient position and landmarks for sciatic nerve (a) and lumbar plexus (b) blocks.

terior (foot dorsiflexion) indicated proximity to the sciatic nerve. A total of $60 \mathrm{ml}, 40 \mathrm{ml}$ carbonated lidocaine $2 \%$ (Xylocaïne $\mathrm{CO}_{2}{ }^{\circ}$, Astra Pharmaceuticals), $20 \mathrm{ml}$ normal saline and adrenaline $0.3 \mathrm{mg}$ (final concentration 1:200,000) was used for every patient. For knee and above knee surgery $35 \mathrm{ml}$ were injected in the lumbar plexus and $25 \mathrm{ml}$ were placed near the sciatic nerve. The proportions were reversed for below knee surgery.

For each patient the following data were collected by the authors: weight, age, sex, site of surgery, time to perform each block, needle depth, speed of onset of the sensory and motor blocks in the territories of the sciatic, femoral, obturator and lateral cutaneous (sensory only) nerves. The motor block was evaluated with a simple scale every five minutes after the end of the second injection: $0=$ absence of movement, $1=$ partial movement and $2=$ normal movement. Signs of sensory and/or motor block were also sought for in the other lower extremity. Surgical positioning and preparation were allowed as soon as a partial progressive sensory block was present. Also collected were duration of surgery, tourniquet-related pain, supplemental peroperative analgesics. Time of appearance of postoperative pain and postoperative analgesic administration were recorded by the outpatient ward nurses on a special form. All operations were performed on an outpatient basis. Quality of anaesthesia was judged; complete (total absence of pain), incomplete (pain that was relieved by $150 \mu \mathrm{g}$ of fentanyl or less) or unsatisfactory (pain that required general anaesthesia).

\section{Lidocaine serum levels}

Lidocaine plasma concentrations were measured in ten of the 45 patients using a fluorometric polarization immuno assay (EPIA, Lidocaine TDX system, Abbott Diagnostic Inc, North Chicago, IL 60064) (specificity: 1.6\% cross-reactivity at a concentration of $10 \mu \mathrm{g} \cdot \mathrm{ml}^{-1}$ of monoethylglycine-xylidine and less than $0.5 \%$ with a group of 16 test compounds, sensitivity: $0.10 \mu \mathrm{g} \cdot \mathrm{ml}^{-1}$, precision: $\mathrm{CV}$ less than $5 \%$. Ten samples were collected for each patient, the following intervals ${ }^{7}$ were used: baseline before the first block and 2, 5, 10,30,60, 90 and $120 \mathrm{~min}$ after the second block. 


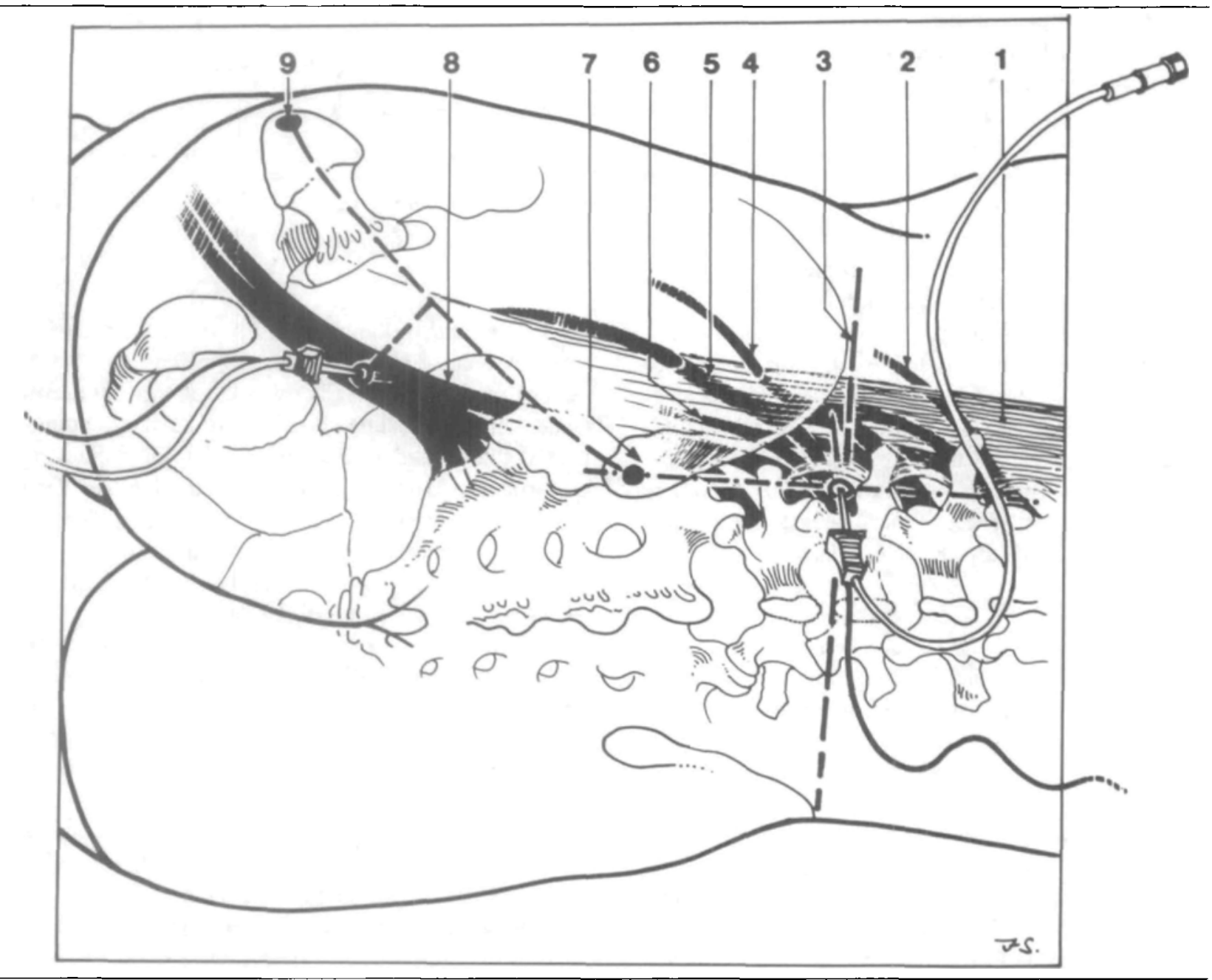

FIGURE 2 Landmarks and structures related to sciatic nerve and lumbar plexus blocks: (1) psoas major muscle, (2) ilioinguinal nerve, (3) line between the upper border of the iliac crests, (4) lateral femoral cutaneous nerve, (5) femoral nerve, (6) obturator nerve, (7) posterior superior iliac spine, (8) sciatic nerve, (9) greater trochanter.

\section{Results}

\section{Combined blocks technique}

Forty-five patients ( 23 women and 22 men) were studied. Ages were between 17 and 69 (mean \pm SD) yr (mean $39 \pm 15.5 \mathrm{yr})$. Weights varied from 43 to $102 \mathrm{~kg}(71$ $\pm 14 \mathrm{~kg})$. Patients all received midazolam $(0.3 \pm 0.11$ $\left.\mathrm{mg} \cdot \mathrm{kg}^{-1}\right)$ and fentanyl $\left(0.74 \pm 0.46 \mu \mathrm{g} \cdot \mathrm{kg}^{-1}\right)$. The sciatic nerve was located from 4 to $10 \mathrm{~cm}(6.4 \pm 1.4 \mathrm{~cm})$ under the skin and the lumbar plexus was at a depth of 5 to $10 \mathrm{~cm}(7.4 \pm 1.3 \mathrm{~cm})$. The time to complete the two blocks varied between 3 and $40 \mathrm{~min}(8 \pm 5.9$ min). The motor block was complete in all three nerves in $12.7 \pm 9.8 \mathrm{~min}$ while the sensory block took $13 \pm$ $8.7 \mathrm{~min}$ to be complete in the four nerves. Of the 45 operations, 33 were at the knee and 22 were distal to the knee. Surgery started $35 \pm 24 \mathrm{~min}$ after the end of the second block. Anaesthesia was complete in 40 of the 45 patients, in five it was judged incomplete but no patient required general anaesthesia. A tourniquet was used in all patients, in six patients it caused a mild discomfort after 22 to $64 \mathrm{~min}$ following cuff inflation (42 $\pm 19 \mathrm{~min}$ ). Operations of up to $105 \mathrm{~min}$ were performed (37 $\pm 19 \mathrm{~min}$ ). Bilateral block was present in four patients, in one patient (patient $\# 9$ in the lidocaine serum measurement group) the contra-lateral block was profound (motor block $=0$ ), in the other three it was partial (motor block =1). Two patients were hospitalized for reasons unrelated to the anaesthesia. Twenty-seven of the 45 patients did not feel pain before leaving the hospital. In the other 16 patients the pain appeared after $242 \pm$ $51 \mathrm{~min}$ (Table 1). The patients left the hospital $337 \pm$ $49 \mathrm{~min}$ after the regional block.

\section{Lidocaine serum concentrations}

On a total of 100 samples, six were lost due to technical 
TABLE I Postoperative analgesic requirement and type of surgery

\begin{tabular}{llr}
\hline Required no analgesics & \\
27 patients & Knee arthroscopy & 12 \\
& Arthroscopic menisectomy & 7 \\
& Knee surgery & 4 \\
& Ankle surgery & 2 \\
& Tibia & 1 \\
& Toe surgery & 1 \\
Required analgesics & & \\
16 patients & Toe surgery & 4 \\
& Arthroscopic menisectomy & 4 \\
& Ankle surgery & 2 \\
& Knee arthroscopy & 2 \\
& Knee surgery & 2 \\
& Tibia & 2 \\
\hline
\end{tabular}

errors. Results of each patient are in Table II. The mean maximum plasma level $\left(C_{\mathrm{MAx}} \pm \mathrm{SD}\right)$ was $3.7 \pm 2.2$ $\mu \mathrm{g} \cdot \mathrm{ml}^{-1}$ and the mean time to attain it (Tmax \pm SD) was $61.7 \pm 66.2 \mathrm{~min}$. Only one patient (\$9) had serum concentrations $>5 \mu \mathrm{g} \cdot \mathrm{ml}^{-1}$.

\section{Discussion}

Epidural and spinal anaesthesia are the most often used regional anaesthetic techniques for lower extremity surgery. Although effective, they offer little selectivity for the operated side and are subject to a number of side effects, such as arterial hypotension, urinary retention and spinal headache. These side effects are undesirable in outpatient surgery. Our study shows that a combination of lumbar plexus and sciatic nerve blocks is a useful alternative for outpatient surgery of a single lower extremity.

We chose to use a combination of blocks instead of a single large volume injection at the level of the lumbar plexus. In his initial description, Winnie used the term "combined lumbosacral plexus block" to illustrate that the two plexuses were blocked by the same injection. However, apart from the work of Vaghadia, ${ }^{8}$ who used a catheter technique, the literature generally suggests using a combination of lumbar plexus and sciatic nerve blocks instead of a single injection technique. ${ }^{3,4,9}$ This issue is unresolved as the two techniques have not been compared prospectively.

All blocks were performed by anaesthetists experienced with the technique or by residents under their supervision. The mean time to perform two blocks, $8.0 \pm 5.9 \mathrm{~min}$, appears to be compatible with clinical practice especially if the blocks are made in an induction room some time before the anticipated time of surgery.

Neurostimulation is of great help in the learning and the practice of these techniques. ${ }^{10}$ Indeed, there are important variations in the depth of the structures, 5 to
$10 \mathrm{~cm}$ for the lumbar plexus and 4 to $10 \mathrm{~cm}$ for the sciatic nerve. However, one modification to our neurostimulation technique might improve the success rate. In a recent study, Kaiser $e t$ al. demonstrated that the efficacy of the block was inversely related to the intensity of threshold amperage. " The best results (100\% success), and shortest latency, were obtained when a current of 0.3 or $0.5 \mathrm{~mA}$ was used. In our study, the intensity was 0.5 to $1.0 \mathrm{~mA}$.

Sensory block of the four nerves was complete in 27 of the 45 patients $13 \pm 8.7 \mathrm{~min}$ after the second injection and motor block was present in 22 patients after $12 \pm$ $9.8 \mathrm{~min}$. The exact time course of the sensory and motor blocks are not available for all patients since we allowed surgical positioning and preparation as soon as a partial progressive sensory block was present. The $35.8 \pm 24$ min delay between the end of the technique and the incision may seem to be long, but it includes all delays between the induction room and the operating room and the surgical installation and disinfection before the incision. During the study, no effort was made to shorten this delay. Only six of the 45 patients complained of mild discomfort due to the tourniquet after $42 \pm 19 \mathrm{~min}$. This was easily dealt with either by reassurance or fentanyl. The surgery's duration was $37 \pm 19 \mathrm{~min}$, one case lasting $105 \mathrm{~min}$ without problem.

All 45 patients were scheduled as outpatients, two were hospitalized after the surgery. Only 16 patients out of the remaining 43 received an analgesic (acetaminophen with or without codeine) before leaving the hospital 242 $\pm 51 \mathrm{~min}$ after the blocks were made. Four of the 45 patients displayed a contralateral extension of the analgesia suggesting an epidural distribution of the local anaesthetic. This is a well recognized complication of the posterior technique of the lumbar plexus block. The incidence of bilateral block varies according to the technique used. It occurs rarely when Winnie's landmarks are used, but the incidence of bilateral blocks can reach $88 \%$ if Chayen's recommendations are opted for. ${ }^{5}$

Although high, the dose of lidocaine used $(680 \mathrm{mg}$ + epinephrine $0.3 \mathrm{mg}$ ) is well within DiFasio's recommendations ${ }^{12}$ for peripheral blocks and close to the 650 $\mathrm{mg}$ ( + epinephrine) used by Elmas and Atanasoff ${ }^{13}$ in a study of combined 3-in-1 and sciatic nerve blocks. A number of publications ${ }^{7,14-18}$ suggest that it is safe to use doses higher than that generally accepted or recommended by the manufacturer. Klein ${ }^{19}$ even reports the use of up to $35 \mathrm{mg} \cdot \mathrm{kg}^{-1}$ of lidocaine for liposuction. This illustrates well the importance of the injection site and technique when recommending a maximum safe dose. Our choice of a single dose for an adult group was based on practical considerations and because there is no clear correlation in the literature between the serum 
TABLE II Serum lidocaine concentrations $\left(\mu \mathrm{g} \cdot \mathrm{ml}^{-1}\right)$

\begin{tabular}{|c|c|c|c|c|c|c|c|c|c|c|}
\hline \multirow[b]{2}{*}{ Patient } & \multirow[b]{2}{*}{ Baseline $†$} & \multicolumn{9}{|c|}{$T i m e^{*}$} \\
\hline & & 2 & 5 & 10 & 30 & 60 & 90 & 120 & 180 & 240 \\
\hline$\# 1$ & 0 & 0.58 & 1.68 & 2.93 & 3.88 & 3.25 & 2.56 & 2.24 & & 1.51 \\
\hline$\# 2$ & 0 & 0.33 & & 1.33 & 2.41 & 2.42 & 2.19 & 2.09 & 2.06 & \\
\hline$\# 3$ & 0 & 1.52 & 2.10 & 3.03 & 2.90 & 2.41 & & 2.04 & 1.97 & \\
\hline$\# 4$ & 0 & & 1.90 & 3.18 & 4.16 & 3.93 & 3.15 & 2.83 & 2.30 & 1.97 \\
\hline \#5 & 0 & 3.94 & 3.88 & 3.68 & 3.59 & 3.13 & 2.64 & 2.53 & 2.29 & 2.04 \\
\hline$\# 6$ & 0 & 1.67 & 2.23 & 2.36 & 2.39 & 2.93 & 2.87 & 2.38 & 1.73 & 1.29 \\
\hline$\# 7$ & 0 & 0.92 & 0.81 & 1.41 & 2.13 & 1.87 & 2.13 & 1.75 & 2.35 & 1.93 \\
\hline \#8 & 0 & 0.18 & 0.26 & 0.36 & 0.80 & 0.95 & 1.27 & 1.38 & 1.66 & \\
\hline$\$ 9$ & 0 & 3.68 & 9.54 & 9.39 & 7.82 & 4.44 & 4.78 & & 3.16 & 2.46 \\
\hline$\# 10$ & 0 & 0.21 & 0.40 & 1.83 & 2.69 & 2.72 & 2.15 & 1.99 & I.69 & 1.58 \\
\hline
\end{tabular}

* Min after the end of the second block.

$\dagger$ Before injection of first block.

lidocaine concentration and patient weight for a given dose. ${ }^{20-24}$

Figure 3 illustrates mean serum concentrations as computed from Table I. The values are well within safe limits. However, the data from two patients ( $\# 5$ and $\# 9$ ) require discussion. Patient \#5 weighed $95.5 \mathrm{~kg}$ and it took 33 min to complete both blocks. Nevertheless the analgesia was complete. This delay resulted in the " 2 minute" serum measurement being made $35 \mathrm{~min}$ after the end of the sciatic nerve block. This situation mimics an early and rapid serum concentration increase, which was not the case. All serum values for this patient were $<3.94$ $\mu \mathrm{g} \cdot \mathrm{ml}^{-1}$, which is regarded as a safe level. Serum concentrations for patient \#9 were higher. Although no signs of local anaesthetic toxicity were noted, three of the measured values $\left(9.54,9.39\right.$ and $\left.7.82 \mu \mathrm{g} \cdot \mathrm{ml}^{-1}\right)$ were $>5$ $\mu \mathrm{g} \cdot \mathrm{ml}^{-1}$ the level that is usually considered to be safe. Of the ten patients who had serum measurements, this was the only one to have signs of a bilateral block. The anaesthesia was bilateral and profound in each leg. Within ten minutes the sensory and motor blocks were complete. The time to perform the two techniques was $<$ three minutes. The speed of progression of the block and its contralateral extension lead us to believe that some form of mechanism similar to an epidural spread was present following the lumbar plexus injection although an intravascular injection cannot be excluded.

\section{Conclusion}

A combination of sciatic nerve and lumbar plexus block by the posterior approach using a neurostimulator is a useful means of providing unilateral anaesthesia for lower extremity surgery. The learning and execution of these blocks are generally easy. The use of lidocaine for these blocks was satisfactory for outpatient surgery and the dose used was adequate and safe. However, if a bilateral

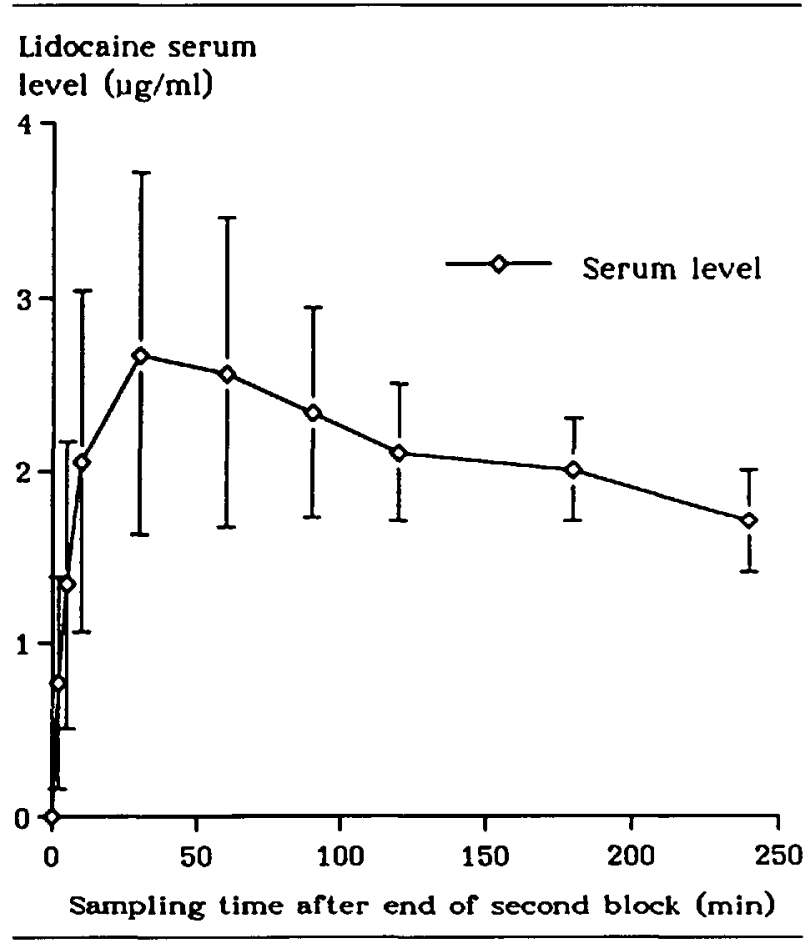

FIGURE 3 Mean $( \pm S D)$ serum lidocaine concentrations after combined blocks of lumbar plexus and sciatic nerve.

block develops the clinician must be aware of the potential for a serum lidocaine concentration $>5 \mu \mathrm{g} \cdot \mathrm{ml}^{-1}$ developing.

\section{Acknowledgments}

The authors wish to thank Mrs. Christiane Côté BSc Inf for her assistance in the data collecting of this work and Mr. David Geadah PhD for the measure of the lidocaine levels. 


\section{References}

1 Winnie AP, Ramamurthy $S$, Durrani $Z$. The inguinal paravascular technic of lumbar plexus anesthesia: the "3-in-1 block." Anesth Analg 1973; 52: 989-96.

2 Winnie AP, Ramamurthy $S$, Durrani $Z$, Radonjic $R$. Plexus blocks for lower extremity surgery. Anesthesiology Review 1974; 11-6.

3 Chayen $D$, Nathan $H$, Chayen $M$. The psoas compartment block. Anesthesiology 1976; 45: 95-9.

4 Parkinson $S K$, Mueller JB, Little $W L$, Bailey $S L$. Extent of blockade with various approaches to the lumbar plexus. Anesth Analg 1989; 68: 243-8.

5 Dalens B, Tanguy A, Vanneuville $G$. Lumbar plexus block in children, a comparison of two procedures in 50 patients. Anesth Analg 1988; 67: 750-8.

6 Labat G. Regional Anesthesia - Its Technique and Clinical Application. $2^{\text {nd }}$ ed. Philadelphia: W.B. Saunders, 1929.

7 Simon MA, Gielen $M J$, Lagerwerf $A J$, Vree TB. Plasma concentrations after high doses of mepivacaine with epinephrine in the combined psoas compartment/sciatic nerve block. Reg Anesth 1990; 15: 256-60.

8 Vaghadia H, Kapnoudhis P, Jenkins LC, Taylor D. Continuous lumbosacral block using a Tuohy needle and catheter technique. Can J Anaesth 1992; 39: 75-8.

9 Brands $E$, Callanan $V$. Continuous lumbar plexus block - analgesia for femoral neck fractures. Anaesth Intensive Care 1978; 6: 256-8.

10 Davies MJ, McGlade DP. One hundred sciatic nerve blocks: a comparison of localisation techniques. Anaesth Intensive Care 1993; 21: 76-8.

11 Kaiser H, Niesel HC, Klimpel L, Bodenmueller $M$. Prilocaine in lumbosacral plexus block - general efficacy and comparison of nerve stimulation amplitude. Acta Anaesthesiol Scand 1992; 36: 692-7.

12 Difazio CA, Woods AM. Pharmacology of local anesthetics. In: Raj PP (Ed.). Practical Management of Pain, $2^{\text {nd }}$ ed., St Louis: Mosby Year Book, 1992: 685-700.

13 Elmas $C$, Atanassoff $P G$. Combined inguinal paravascular (3-in-1) and sciatic nerve blocks for lower limb surgery. Reg Anesth 1993; 18: 88-92.

14 Moore DC, Mather LE, Bridenbaugh L, Balfour RI, Lysons $D F$, Horton $W G$. Arterial and venous plasma levels of bupivacaine following peripheral nerve blocks. Anesth Analg 1976; 55: 763-8.

15 Moore DC, Bridenbaugh LD, Thompson GE, Balfour RI, Horton WG. Bupivacaine: a review of 11,080 cases. Anesth Analg 1978; 57: 42-53.

16 Neill $R S$, Watson $R$. Plasma bupivacaine concentrations during combined regional and general anaesthesia for resection and reconstruction of head and neck carcinomata. $\mathrm{Br}$ J Anaesth 1984; 56: 485-91.

17 Tuominen M, Rosenberg PH, Kalso PH. Blood levels of bupivacaine after single dose, supplementary dose and dur- ing continuous infusion in axillary plexus block. Acta Anaesthesiol Scand 1983; 27: 303-6.

18 Misra U, Pridie AK, McClymont C, Bower S. Plasma concentrations of bupivacaine following combined sciatic and femoral 3 in 1 nerve blocks in open knee surgery. $\mathrm{Br} \mathbf{J}$ Anaesth 1991; 66: 310-3.

19 Klein JA. Tumescent technique for regional anesthesia permits lidocaine doses of $35 \mathrm{mg} / \mathrm{kg}$ for liposuction. J Dermatol Surg Oncol 1990; 16: 248-63.

20 Rowland $M$, Thomson PD, Guichard A, Melmon KL. Disposition kinetics of lidocaine in normal subjects. Ann N Y Acad Sci 1971; 179: 383-98.

21 Tucker GT, Mather LE. Pharmacokinetics of local anaesthetic agents. Br J Anaesth 1975; 47: 213-24.

22 Robison C, Ray DC, McKeown DW, Buchan AS. Effect of adrenaline on plasma concentrations of bupivacaine following lower limb nerve block. Br J Anaesth 1991; 66: 228-31.

23 Pihlajamäki $K K$. Inverse correlation between the peak venous serum concentration of bupivacaine and the weight of the patient during interscalene brachial plexus block. $\mathrm{Br} \mathrm{J}$ Anaesth 1991; 67: 621-2.

24 Scott $D B$, Cousins $M J$. Clinical pharmacology of local anesthetic agents. In: Cousins MJ, Bridenbaugh PO (Eds.). Neural Blockade, Philadelphia: J.B. Lippincott Co., 1980: 86-121. 